\title{
Университеты в России: взгляд изнутри
}

Рецензия на книгу: Кузьминов Я.И., Юдкевич М.М. (2021) Университеты в России: как это работает. М.: Высшая школа экономики.

\section{Е.В. ДЕНИСОВА-ШМИДТ*}

\begin{abstract}
*Елена Викторовна Денисова-Шмидт - доктор философских наук, научный сотрудник, Университет Санкт-Галлена, Швейцария; Центр по изучению международного высшего образования при Бостонском колледже, Бостон, США, elena.denisova-schmidt@unisg.ch, https://orcid.org/0000-0001-8234-4437
\end{abstract}

Цитирование: Денисова-Шмидт Е.В. (2022) Университеты в России: взгляд изнутри // Мир России. Т. 31. № 1. С. 203-209. DOI: 10.17323/1811-038X-2022-31-1-203-209

\begin{abstract}
Аннотация
Книга «Университеть в России: как это работает» является результатом совместной пятилетней работь Ярослава Кузьминова и Марии Юдкевич. В рецензии затрагиваются лишь некоторые из тезисов, представленных в книге: это переход из иколь в вузы и проблемы средней школь вообще, сравнение кафедр российских университетов с оригинальной немецкой моделью, а также равные возможности как в получении высшего образования, так и в дальнейшей научной карьере. Очень подкупает откровенность авторов при описании некоторых правил игры академического рынка, упоминании коррупции, а также артикулячฺи проблем академического мошенничества и имитации работы вузов для достижения формальных показателей.
\end{abstract}

Ключевые слова: Россия, университеты, реформы, история, наука, студенчество, профессорско-преподавательский состав, интернационализаџия

Как устроены университеты в России, как тесно взаимосвязана система высшего образования со всем тем, что происходит в обществе, как важен исторический, социальный и экономический контекст для понимания тех или иных трендов в образовании - обо всем этом можно прочесть в новой книге Ярослава Кузьминова и Марии Юдкевич «Университеты в России: как это работает», вышедшей летом 2021 г. Оба автора - представители Национального исследовательского университета «Высшая школа экономики» (НИУ ВШЭ), одного из ведущих

Статья поступила в редакцию в октябре 2021 г. 
вузов страны, уверенно занимающего лидирующие позиции на мировой арене; НИУ ВШЭ выступил инициатором ряда кардинальных реформ в российском академическом сообществе: найма международных специалистов, открытого конкурса на занятие академических позиций на внутреннем рынке, перехода от кафедральной к департаментской структуре, эффективного контракта и некоторых других. Оба исследователя являются авторами/соавторами/научными редакторами целого ряда книг по глобальным проблемам высшего образования, таким как привлечение иностранных ученых и преподавателей, академические контракты и зарплаты, университетские рейтинги, инбридинг, подготовка аспирантов и др. [Altbach et al. 2012; Altbach et al. 2013; Yudkevich et al. 2015a; Yudkevich et al. 2015b; Yudkevich et al. 2016; Yudkevich et al. 2017; Yudkevich et al. 2019; Yudkevich et al. 2020].

Рецензируемая книга состоит из десяти глав, каждая из которых посвящена определенным аспектам в области высшего образования в России, например студентам (глава 6 «Студенты и образовательный процесс»), профессорско-преподавательскому составу (глава 7 «Академическая профессия и контракты»), научным исследованиям (глава 8 «Наука в российских университетах: история изгнания и возвращения»), международному сотрудничеству (глава 10 «Интернационализация»). Все главы начинаются с небольшой аннотации и перечня ключевых фактов и заканчиваются плавным переходом в следующую главу, но каждую из них можно рассматривать и как отдельную единицу. Особо отмечу очень подробный экскурс в историю - этому посвящены первые две главы книги.

Свое размышление над книгой мне хотелось бы построить, следуя логике авторов, утверждающих, что «<..> понять собственную национальную систему образования невозможно без понимания того, как устроены системы других стран» [Кузьминов, Юдкевич 2021, с. 24], и расширив некоторые тезисы Ярослава Кузьминова и Марии Юдкевич. Так, одной из особенностей российской модели высшего образования авторы называют более короткий срок обучения в старшей общеобразовательной школе вкупе с самыми продолжительными в мире летними каникулами [Кузьминов, Юдкевич 2021, с. 20]. Российская школьная система действительно отличается продолжительными летними каникулами по сравнению с системами многих других стран, но если сравнить годовой план каникул, например, школьников ФР ${ }^{1}$, то он примерно соответствует общему числу свободных дней российских школьников: осенние каникулы (1 неделя), каникулы на Рождество (2,5 недели), каникулы на карнавал (1 неделя), каникулы на Пасху (2 недели), каникулы на Троицу (2 недели), летние каникулы (6 недель), а также большее количество праздничных дней и наличие так называемых подвижных дней - дополнительных выходных (примерно 4-5 дней в течение всего учебного года). Учебная неделя в немецких школах длится, как правило, только пять дней. В Германии, так же как и в России, ученики, окончившие девять классов, уже могут получать среднее специальное образование.

Данная особенность, по мнению авторов, объясняет высокий процент общеобразовательных дисциплин в программах высшего профессионального образования российских вузов - до 25\% [Кузьминов, Юдкевич 2021, с. 20]. Но во многих вузах других стран тоже есть похожие требования: например, в Университете

1 Здесь нужно отметить, что система образования в ФРГ носит децентрализованный характер. Расписание каникул указано для земли Баден-Вюртемберг. В других землях может не быть, например, каникул на карнавал. 
Санкт-Галлена в Швейцарии у студентов ${ }^{2}$ предметы общеобразовательного цикла также составляют $25 \%$ учебного плана. Первокурсникам предлагаются предметы на выбор из различных областей знаний (истории, философии, психологии, социологии), на старших ступенях это более тематические курсы (по медиа, культуре, истории, регионоведению, ответственности (например, социальной ответственности бизнеса), креативности, праву и технологиям); есть курсы по риторике, компьютерной грамотности, академическому письму; обязательно изучение иностранных языков. В настоящий момент университет предлагает курсы на различных ступенях (A1-C1) по десяти иностранным языкам: английскому, немецкому, французскому, итальянскому, португальскому, испанскому, японскому, китайскому, арабскому и русскому.

Средние школы в России очень неоднородны. Вероятно, поэтому неоднородны и выпускники российских школ, дальнейшая образовательная мобильность которых в большей степени определяется тем школьным образованием, которое они получают по месту жительства, и в значительной степени - ресурсами семьи. Нужно отметить, что в других странах эта особенность институционализирована: например, в Швейцарии обязательное школьное образование длится 11 лет. Начальная ступень, включая два года детского сада, продолжается 8 лет; затем в зависимости от кантона ${ }^{3}$ ученики либо получают распределение, либо сдают вступительные экзамены и поступают в другие типы школ; таким образом в возрасте примерно 12 лет определяется дальнейшая образовательная траектория школьников. Сегодня обязательное школьное образование в Швейцарии получают около 90\% учащихся, и только треть из них находится на обучении в гимназиях / кантональных школах, по окончании которых они сдают соответствующие экзамены, получают аттестат зрелости (Matura) и, таким образом, право поступать в вузы (см. более подробно [Денисова-Шмидт, Шмидт 2021]). Однако средние школы в России, скорее всего, уже устали от реформ последних лет, хотя в перспективе они, безусловно, нужны, но тот факт, что «российские родители оказывают существенную помощь своим детям при обучении в школе: более $70 \%$ родителей ежедневно контролируют выполнение домашних заданий» [Кузьминов, Юдкевич 2021, с. 319], вызывает серьезную озабоченность, и, на мой взгляд, экспертам, принимающим решения, следует уже сейчас обратить на это серьезное внимание.

Кафедра как ключевая единица вуза была заимствована российской системой из немецкой модели университета, но при этом она существенно отличается от оригинала. К очень подробному описанию российских особенностей («Кафедральная система и ее альтернативы» [Кузьминов, Юдкевич 2021, с. 541-545]) хотелось бы добавить еще три существенных элемента, которые не были перенесены в российские вузы. Во-первых, заведующий кафедрой в немецких вузах является собственником данной кафедры в прямом смысле этого слова, т. е. часть академического контракта включает количество штатных единиц, ставя всех сотрудников кафедры в зависимость от самого заведующего. Карьера на кафедре по вертикали, как это происходит в российских вузах (ассистент - преподаватель - старший преподаватель - доцент - профессор), практически исключена. Более того, законодательство ФРГ запрещает работать в одном и том же немецком вузе более 12 лет.

2 Подготовка студентов-бакалавров осуществляется по нескольким направлениям: бизнес, экономика, международные отношения и право.

3 Так же как и в ФРГ, в Швейцарии система образования децентрализована. 
Это правило не распространяется на заведующих, которые, как правило, получают свою должность пожизненно. Второе существенное отличие - это то, что для получения должности заведующего кафедрой для профессора в Германии важны, помимо профессиональных компетенций, еще два пункта - состояние здоровья и благонадежность. Представители Левой партии часто жалуются на то, что их карьера не складывается именно из-за их партийной принадлежности, т. е. «неблагонадежности». И последнее отличие: докторская диссертация (Habilitation) пока все еще является в большинстве случаев формальным критерием для претендентов на эту должность. Исследователь, успешно защитивший докторскую диссертацию и пока еще не получивший свою кафедру, что, кстати, может никогда и не произойти, должен регулярно (чаще всего ежегодно) подтверждать свою ученую степень путем чтения лекций, иначе он будет ее лишен. Вуз, где проходила защита, обязан предоставить соответствующие часы, но не обязан предоставлять зарплату (гонорар) и компенсировать возможные командировочные расходы.

Очень подкупает откровенность авторов книги «Университеты в России: как это работает» при описании некоторых правил игры академического рынка, при упоминании коррупции, а также артикуляция таких проблем, как имитация работы вузов для достижения формальных показателей и академическое мошенничество. Правда, мне хотелось бы увидеть немного больше таких подразделов, как «Проблемы недобросовестного поведения» [Кузьминов, Юдкевич 2021, с. 371-374], где авторы очень подробно описывают причины обмана среди студенческой молодежи. Подобное нечестное поведение в академической сфере, о чем, кстати, много пишут и на страницах журнала «Мир России» (см. последние публикации [Макеева и др. 2020; Трубникова 2020; Denisova-Schmidt 2020; Denisova-Schmidt 2021]), может иметь драматические последствия не только для академического сообщества, но и для страны в целом. Примером служит вяло идущая вакцинация против коронавируса в России, которую можно смело связать, наряду с некоторыми другими причинами, с недоверием в обществе к достижениям отечественной науки.

То, о чем авторы книги могли бы написать более подробно, - это более или менее равные возможности как в получении высшего образования, так и в дальнейшей научной карьере для обоих полов: «Уже много десятилетий в России нет проблемы дискриминации женщин в доступе к высшему образованию» [Кузьминов, Юдкевич 2021, с. 347]; «Сегодня среди преподавателей российских вузов женщины составляют более половины» [Кузьминов, Юдкевич 2021, с. 399]. Так, например, в некоторых западноевропейских странах в опросах, касающихся социально-демографических характеристик студенческого сообщества, в разделе «семья» отсутствует графа «образование и социальный статус матери». Причем это не признак того, что в выборку входят только дети-сироты. В немецкоязычной Европе существуют (пока негласные) квоты на продвижение женщин по карьерной лестнице, которые создают позитивную дискриминацию коллег-мужчин. Это и неудивительно, потому что, например, в Венском университете экономики и бизнеса первая женщина-профессор, Ренате Ратмайр, была принята на работу только в 1989 г. Впоследствии она с юмором вспоминала, как ей долго приходили письма из администрации вуза с обращением «уважаемый господин», а в приглашениях на традиционный бал университета было указано «возьмите с собой супругу» [Hall of Femmes 2015]. В этом плане российским вузам есть чем гордиться. 
Книга «Университеты в России: как это работает», которую можно без преувеличения назвать энциклопедией высшего образования в России, будет интересна и полезна широкому кругу читателей, студентам, исследователям, экспертному сообществу.

\section{Список источников}

Денисова-Шмидт Е., Шмидт Т. (2020) Русский язык в Швейцарии // Норман Б., Куссе X. (ред.) Русский язык за пределами России: коллективная монография. Екатеринбург; М.: Кабинетный ученый. С. 270-292.

Кузьминов Я.И., Юдкевич М.М. (2021) Университеты в России: как это работает. М.: ВШЭ.

Макеева А.А., Цивинская А.О., Соколов М.М., Соколова Н.А., Губа К.С. (2020) Некорректные заимствования в российских докторских диссертациях: сколько, где и у кого? // Мир России. Т. 29. № 2. С. 27-48. DOI: 10.17323/1811-038X-2020-29-2-27-48

Трубникова Е.И. (2020) Проект 5-100: взгляд через призму теории институциональной коррупции // Мир России. Т. 29. № 2. С. 72-91. DOI: 10.17323/1811-038X-2020-29-2-72-91

Altbach P.G., Reisberg L., Yudkevich M., Androushchak G., Pacheco I. (eds.) (2012) Paying the Professoriate. A Global Comparison of Compensation and Contracts, London: Routledge.

Altbach P.G., Androushchak G., Kuzminov Yu., Yudkevich M., Reisberg L. (eds.) (2013) The Global Future of Higher Education and the Academic Profession: The Brics and the United States, New York: Palgrave Macmillan.

Denisova-Schmidt E. (2020) The End of the Academic Profession in Russia? // Mir Rossii, vol. 29, no 3, pp. 86-95. DOI: 10.17323/1811-038X-2020-29-3-86-95

Denisova-Schmidt E. (2021) Responses to the Challenges of Training and Retaining Scholars in Russian Academia // Mir Rossii, vol. 30, no 3, pp. 174-187. DOI: $10.17323 / 1811-038 X-2021-30-3-174-187$

Hall of Femmes: Renate Rathmayr (2015) // Wirtschaftsuniversität Wien, Mai 13, 2015 // https://blog.wu.ac.at/2015/05/hall-of-femmes-renate-rathmayr/, дата обращения 31.10.2021.

Yudkevich M., Altbach P.G., Rumbley L.E. (eds.) (2015a) Young Faculty in the Twenty-First Century. International Perspectives, Albany; NY: State University of New York Press.

Yudkevich M., Altbach P.G., Rumbley L.E. (eds.) (2015b) Academic Inbreeding and Mobility in Higher Education. Global Perspectives, New York: Palgrave Macmillan.

Yudkevich M., Altbach P.G., Rumbley L.E. (eds.) (2016) The Global Academic Rankings Game. Changing Institutional Policy, Practice, and Academic Life, London: Routledge.

Yudkevich M., Altbach P.G., Rumbley L.E. (eds.) (2017) International Faculty in Higher Education: Comparative Perspectives on Recruitment, Integration, and Impact, London: Routledge.

Yudkevich M.M., Balbachevsky E., Finkelstein M.J., Jayaram N., Jones G.A., Kehm B.M., Mao D., Musselin C., Scott P., Yan F., Yonezawa A. (eds.) (2019) Professorial Pathways: Academic Careers in a Global Perspective, Baltimore: Johns Hopkins University Press.

Yudkevich M., Altbach P., de Wit H. (eds.) (2020) Trends and Issues in Doctoral Education Worldwide: An International Research Inquiry, London: Routledge. 


\title{
Universities in Russia: An Insider's Perspective
}

\author{
Book Review: Kuzminov Y., Yudkevich M. (2021) Universities in Russia: \\ How It Works, Moscow: HSE (in Russian).
}

\section{E.V. DENISOVA-SCHMIDT*}

\begin{abstract}
*Elena V. Denisova-Schmidt - DSc in Philosophy, Research Associate, University of St. Gallen (HSG), St. Gallen, Switzerland; Research Fellow, Boston College Center for International Higher Education, Boston, USA, elena.denisova-schmidt@unisg.ch, https://orcid.org/0000-0001-8234-4437

Citation: Denisova-Schmidt E.V. (2022) Universities in Russia: An Insider's Perspective. Mir Rossii, vol. 31, no 1, pp. 203-209 (in Russian). DOI: $10.17323 / 1811-038 \mathrm{X}-2022-31-1-203-209$
\end{abstract}

\begin{abstract}
This article reviews the book 'Universities in Russia: How It Works' by Yaroslav Kuzminov and Maria Yudkevich, both representing the rectorate of HSE University - one of Russia's leading research universities, which is becoming increasingly successful on the world stage. The university has initiated and implemented several crucial reforms within Russian academia. Both authors also engage in research and have made significant contributions to the study of global higher education in Russia and beyond. The book is the result of five years of intensive joint work. It consists of ten chapters, each zooming in on a specific aspect of higher education in Russia, such as: students (chapter 6, 'Students and the Educational Process'), faculty (chapter 7, 'The Academic Profession and Contracts'), research (chapter 8, 'Science in Russian Universities: The History of Exile and Return'), and international cooperation (chapter 10, 'Internationalization'). The book focuses on the present day, but two separate chapters consider the historical aspect (chapter 1, 'Historical Foundations of the Russian Higher Education System,' and chapter 2, 'Higher Education of the Soviet Era and the First Post-Soviet Decade'). This review engages with only some of the ideas presented in the book: the transition from school to university and the problems of secondary education in general, a comparison of the chair system (kafedry) at Russian universities with the original German model, and gender inequality in higher education and academia. To the authors' credit, they openly discuss a few of the rules of the game in academia, as well as more sensitive issues such as corruption, academic fraud, and the imitative behavior of some Russian universities. The book can be considered an encyclopedia of higher education in Russia. It will appeal and be useful to a wide range of readers, including students, researchers, and the expert community.
\end{abstract}

Keywords: Russia, universities, reforms, history, science, students, faculty, internationalization

\section{References}

Altbach P.G., Reisberg L., Yudkevich M., Androushchak G., Pacheco I. (eds.) (2012) Paying the Professoriate. A Global Comparison of Compensation and Contracts, London: Routledge.

Altbach P.G., Androushchak G., Kuzminov Yu., Yudkevich M., Reisberg L. (eds.) (2013) The Global Future of Higher Education and the Academic Profession: The Brics and the United States, New York: Palgrave Macmillan. 
Denisova-Schmidt E. (2020) The End of the Academic Profession in Russia? Mir Rossii, vol. 29, no 3, pp. 86-95. DOI: 10.17323/1811-038X-2020-29-3-86-95

Denisova-Schmidt E. (2021) Responses to the Challenges of Training and Retaining Scholars in Russian Academia. Mir Rossii, vol. 30, no 3, pp. 174-187. DOI: 10.17323/1811-038X-2021-30-3-174-187

Denisova-Schmidt E., Schmidt T. (2020) Russian Language in Switzerland. The Russian Language outside Russia: A Collective Monograph (eds. Norman B., Kusse H.), Yekaterinburg; Moscow: Kabinetnyi uchenyi, pp. 270-292 (in Russian).

Kuzminov Ya.I., Yudkevich M.M. (2021) Universities in Russia: How It Works, Moscow: HSE (in Russian).

Makeeva A., Tsivinskaya A., Sokolov M., Sokolova N., Guba K. (2020) Plagiarism in Russian Doctoral Dissertations: How Much, Where, and in Whose Work? Mir Rossii, vol. 29, no 2, pp. 27-48 (in Russian). DOI: 10.17323/1811-038X-2020-29-2-27-48

Trubnikova E. (2020) Project 5-100: A View through the Prism of the Theory of Institutional Corruption. Mir Rossii, vol. 29, no 2, pp. 72-91 (in Russian). DOI: 10.17323/1811-038X-2020-29-2-72-91

Hall of Femmes: Renate Rathmayr (2015) Wirtschaftsuniversität Wien, Mai 13, 2015. Available at: https://blog.wu.ac.at/2015/05/hall-of-femmes-renate-rathmayr/, accessed 31.10.2021.

Yudkevich M., Altbach P.G., Rumbley L.E. (eds.) (2015a). Young Faculty in the Twenty-First Century. International Perspectives, Albany; NY: State University of New York Press.

Yudkevich M., Altbach P.G., Rumbley L.E. (eds.) (2015b) Academic Inbreeding and Mobility in Higher Education. Global Perspectives, New York: Palgrave Macmillan.

Yudkevich M., Altbach P.G., Rumbley L.E. (eds.) (2016) The Global Academic Rankings Game. Changing Institutional Policy, Practice, and Academic Life, London: Routledge.

Yudkevich M., Altbach P.G., Rumbley L.E. (eds.) (2017) International Faculty in Higher Education: Comparative Perspectives on Recruitment, Integration, and Impact, London: Routledge.

Yudkevich M.M., Balbachevsky E., Finkelstein M.J., Jayaram N., Jones G.A., Kehm B.M., Mao D., Musselin C., Scott P., Yan F., Yonezawa A. (eds.) (2019) Professorial Pathways: Academic Careers in a Global Perspective, Baltimore: Johns Hopkins University Press.

Yudkevich M., Altbach P., de Wit H. (eds.) (2020) Trends and Issues in Doctoral Education Worldwide: An International Research Inquiry, London: Routledge. 